Document downloaded from:

http://hdl.handle.net/10251/43601

This paper must be cited as:

Martínez Lluch, A.; Vegas López-Manzanares, F.; Mileto, C.; Diodato, M. (2013).

Microwaves as a Remedial Treatment of Wood. Advanced Materials Research. 778:620627. doi:10.4028/www.scientific.net/AMR.778.620.

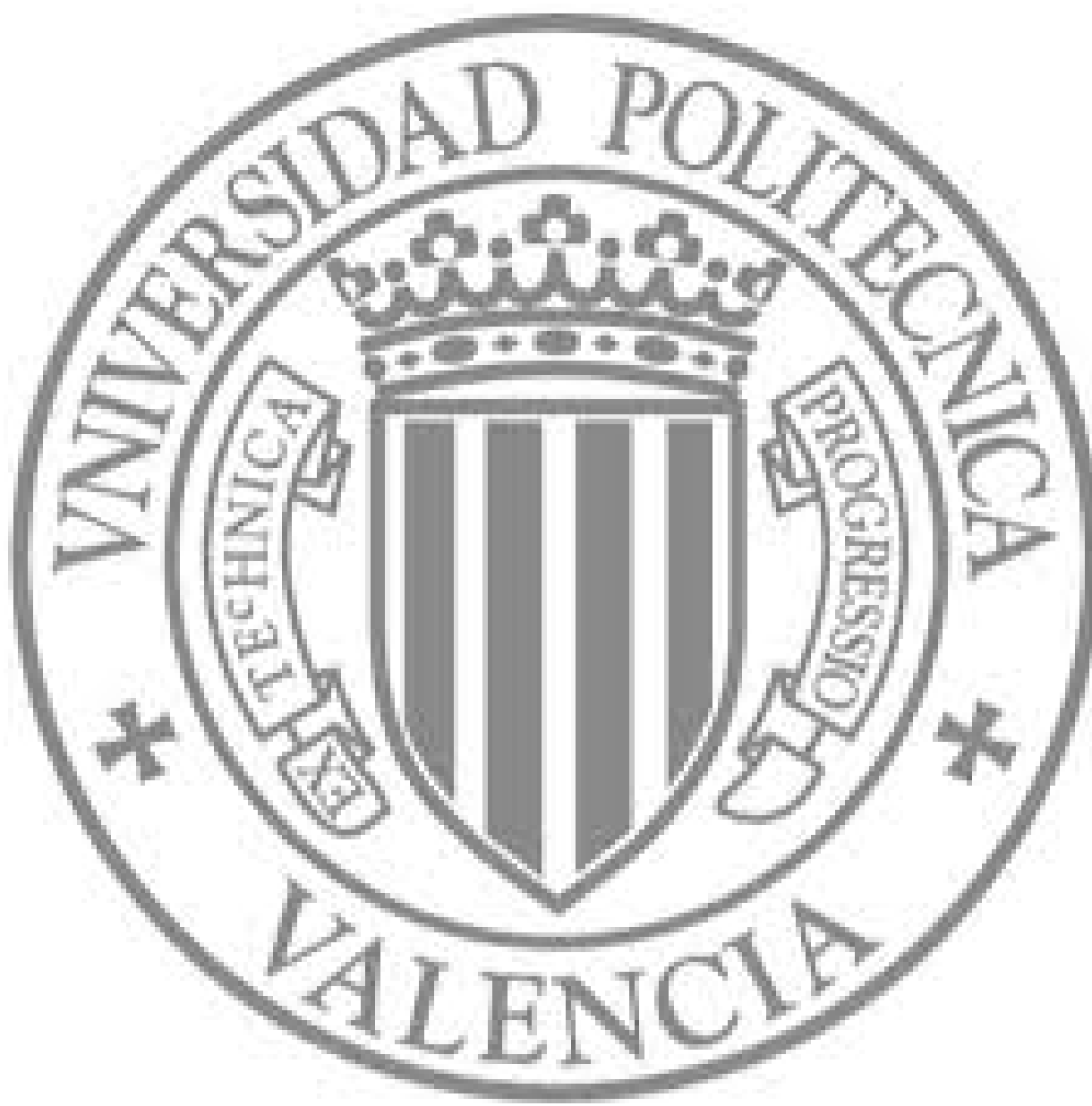

The final publication is available at

http://dx.doi.org/10.4028/www.scientific.net/AMR.778.620

Copyright Trans Tech Publications 


\title{
Microwaves as a Remedial Treatment of Wood
}

\author{
Martínez Lluch Antonio ${ }^{1, a}$, Vegas López-Manzanares Fernando ${ }^{2, b}$, \\ Mileto Camilla ${ }^{2, \mathrm{c}}$, Diodato Maria ${ }^{2, \mathrm{~d}}$ \\ ${ }^{1}$ Dry-parasite, Avda. Mare Nostrum 7 - 46120 Alboraya - Valencia, Spain \\ ${ }^{2}$ IRP-UPV, Edificio 8B, Acceso L, Nivel 0, Camino de Vera s/n - 46022 Valencia, Spain \\ a amartinez@valenciadelcid.com, ${ }^{b}$ fvegas@cpa.upv.es, \\ ccami2@cpa.upv.es, ${ }^{\mathrm{c}}$ m.diodato@hotmail.com
}

Keywords: microwaves, treatment, xylophagous insects, moisture, Art Nouveau, Valencia

\begin{abstract}
A pilot experiment of microwave treatment was carried out on an Art Nouveau residential building erected at the beginning of the $20^{\text {th }}$ century in Valencia, Spain. The timber structure was affected by a combined damage caused by Anobium punctatum (common furniture beetle or common house borer) and Kalotermes flavicollis (yellownecked dry-wood termite). After performing an exhaustive preliminary study on the building and analyzing the different alternatives of wood treatment, it was decided to use a microwave machine especially designed to eliminate this type of wood boring insects.

This machine generates microwaves, a type of electromagnetic radiation, with a frequency of $2.45 \mathrm{GHz}$. This circumstance makes it possible to produce a high-frequency alternating electric field that causes the rotation of the molecular dipoles of water. Because of this continuous rotation the temperature of the water rises considerably.

By heating up the humidity inside a living being, as in the case of xylophagous insects, an artificial fever in the body is generated, and since the animal is not capable of tolerating this temperature, it dies.

In order to eliminate xylophagous insects, the wood moisture content (usually between $10 \%$ and $12 \%$ ) and the presence of water in wood boring insects (around 90\%) must be taken into account. Due to the greater content of humidity the increase of the temperature is higher and quicker in insects than wood.

Prior to this pilot intervention, several research works were carried out with the same microwave machine, especially on wooden works of art. In all these studies it was observed that no damage was caused either to the wood or to the finish of the works of art including pigments, polishes, stains etc. On the other hand, $100 \%$ efficacy was achieved in the elimination of xylophagous insects.

This article describes the design, experimentation and perfecting process of this microwave machine and its pilot application on structural timber in an Art Nouveau residential building, bringing the knowledge of the laboratory on-site and evaluating the differences in the procedures.
\end{abstract}

\section{The Microwaves Treatment}

Introduction to Microwaves. The electromagnetic spectrum is the range of all existing wavelength and frequencies of electromagnetic waves, from gamma rays to radio waves passing through visible light. In this spectrum the waves with a wavelength range between $1 \mathrm{~mm}$ and $1 \mathrm{~m}$ and a frequency range between $0.3 \mathrm{GHz}$ and $300 \mathrm{GHz}$ are called microwaves. In ovens, as well as in the wood treatment against xylophagous insects described in this article, an electromagnetic radiation with the frequency of $2.45 \mathrm{GHz}$ is used [1].

These microwaves interact with matter at a molecular scale producing molecular rotation. In the molecule of water, $\mathrm{H}_{2} \mathrm{O}$, the covalent bonds between the oxygen atom and the two hydrogen atoms create an angle of approximately $105^{\circ}$. Due to their own small charge, these three atoms form a 
polar molecule that permanently have a positive pole towards the hydrogen atoms and a negative pole in the direction of the oxygen atom.

All the polar molecules of water align themselves to the electromagnetic field. As this field is constantly oscillating, changing its direction because of the microwaves, the mentioned molecules incessantly rotate aligning themselves to the ever-changing field. This rotation and the interactions between the molecules increase the temperature that is the kinetic energy of the particles in the substance, converting the energy of the electromagnetic field in heat.

The warming process due to microwaves is active in all materials but is more intense in the case of dipoles as water, so its ratio, in both wood and insects, is extremely relevant for the effectiveness of the treatment.

As the moisture content in wood is usually around $12 \%$ while the presence of water in wood boring insects rises up to $90 \%$, the heating effect of microwaves is especially concentrated on the insects. Therefore the temperature of the water inside the body of the insects rapidly increase provoking a sort of artificial fever, more than $60^{\circ} \mathrm{C}$, until the animal cannot bear it anymore and dies (Fig. 1).

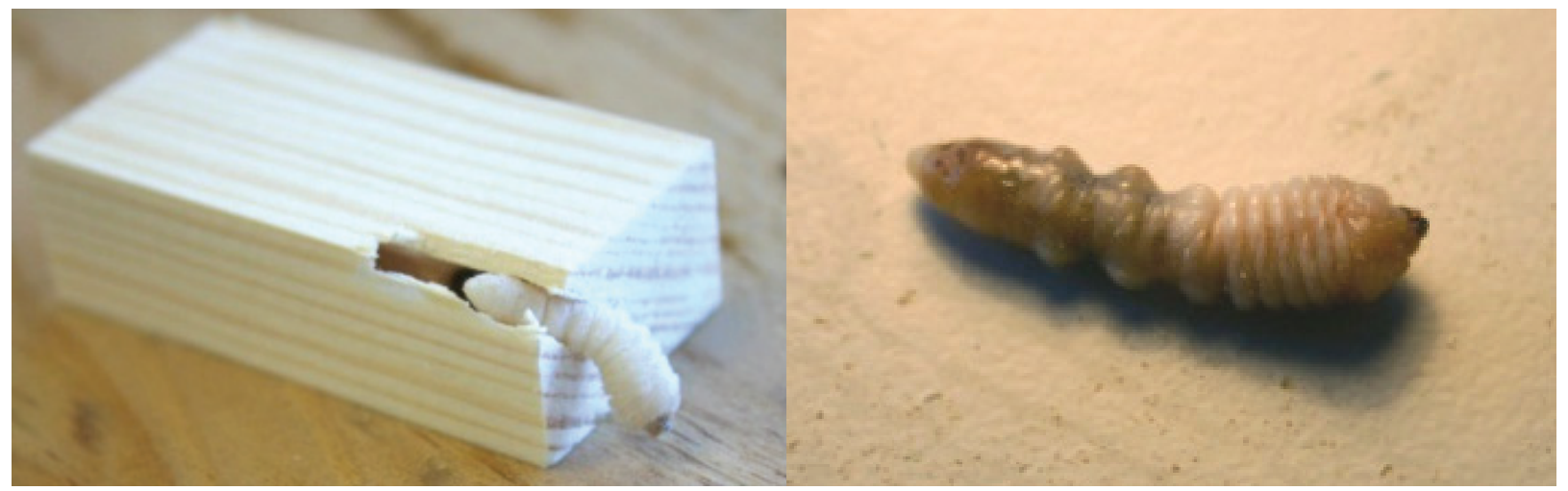

Fig. 1. Larva of a Hylotrupes bajulus before and after applying microwaves

The Dryparasite System. The wood treatment against xylophagous insects using microwaves described above was developed by one of the authors under the name Dryparasite (patent $\mathrm{n}^{\circ}$ 200101089 / Spain)

This system uses a device which components are: a special metal insulated box where 220 volt electric current is converted into 4000 volt by a transformer and microwaves are generated by a magnetron, a specially designed square antenna that reaches the element to be treated and special coaxial cables that connect the two elements (Fig. 2).
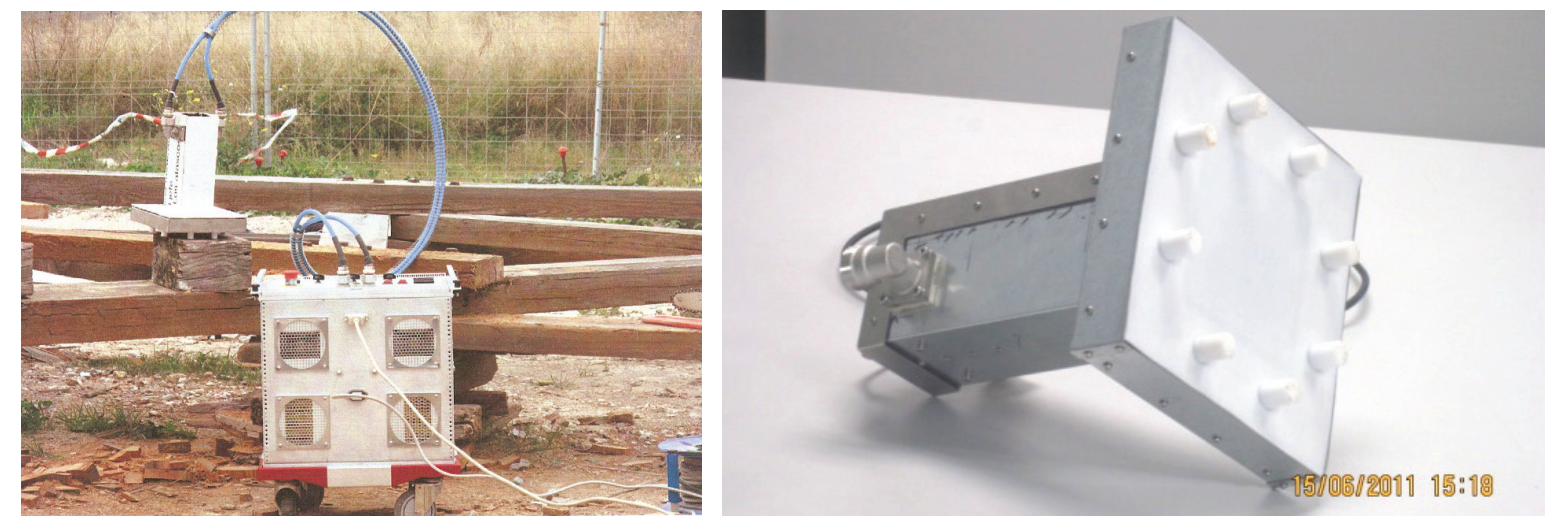

Fig. 2. Dryparasite device, antenna emitting microwaves

Usually microwaves are emitted through the antenna with a linear polarization in which case microwaves only come out from a vertical central band; this area occupies the central third or quarter of the square antenna's surface. This way of emitting the waves only facilitates the penetration of the waves if they are oriented as the grain of the wood. 
In the case of the mentioned system, the microwaves are transmitted with circular polarization and therefore come out through the whole surface of the antenna acting on a larger surface, penetrating the wood regardless to the direction of the grain. This way of emitting microwaves is due both to the design of the antenna itself and the use of two magnetrons instead of one (Fig. 3).
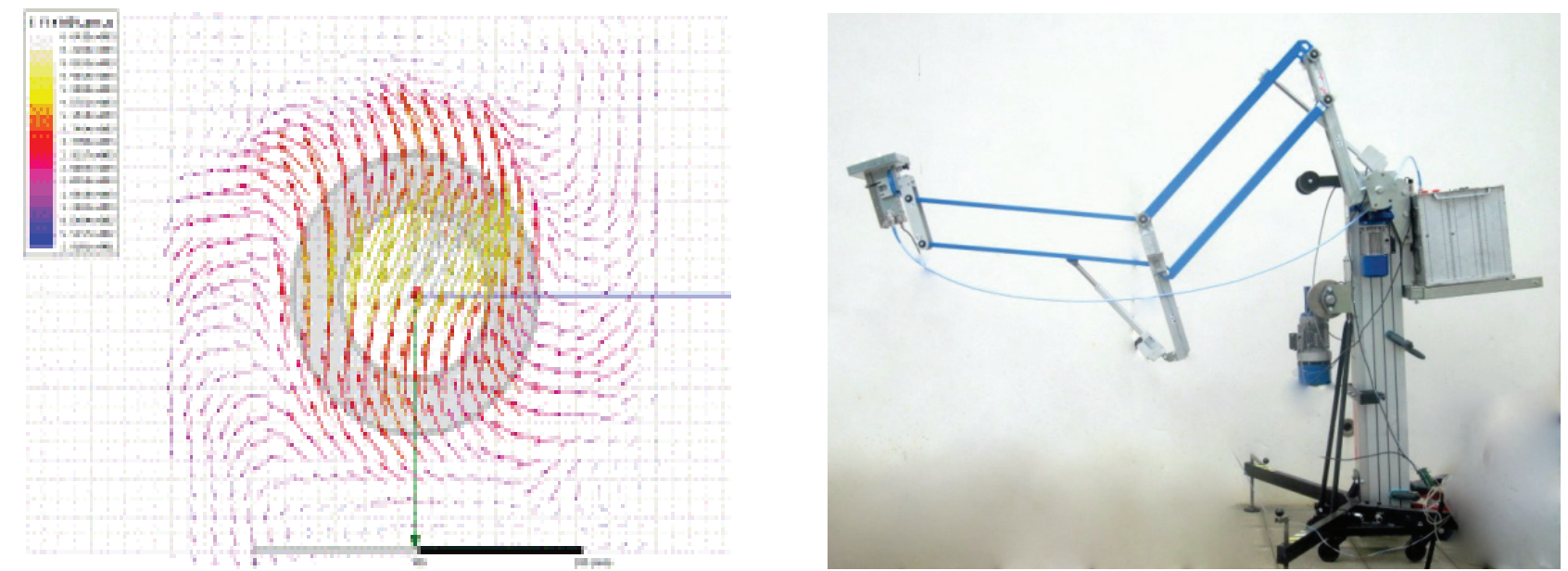

Fig. 3. Circular microwave emission, articulated arm with the microwave device

This microwave system makes it possible either treat wood holding the antenna with the hand or place the antenna on a specially designed articulated arm. In this second case, the articulated arm executes the work autonomously, after being programmed (Fig. 3). This possibility is very useful for larger timber structure, especially in architectural heritage [2].

In order to control the correct and efficient employment of the system, laboratory research was carried out during the final design of the device. These tests with Hylotrupes bajulus were performed at the Universitat Politècnica de València in association with the company DP System S.L., owner of the Dryparasite microwave system. They were focused on artistic supports like painted pieces and boards. These tests resulted with $100 \%$ effectiveness, so that, after applying the microwave, no living insect could be found in the samples. Moreover, after the treatment, appropriate tests proved that neither were the physical and mechanical properties of the wood altered nor did the wood suffer any deformation or movement of any kind [3].

The final purpose of the research done during almost three years at the Instituto de Restauración del Patrimonio of the Universitat Politècnica de València was to verify the behavior of different finishes applied on the wood like paint, putty, binding agents, pigments, etc. Also in this case, with the proper application protocol, none of these finishes suffered any alteration caused by the application of microwave $[4,5,6]$.

In all the mentioned tests, the crucial point was the measurement of both interior and exterior temperature of wood. The information was gathered by using thermographic cameras and thermocouples so that the distribution of the microwaves inside the wood could be studied (Fig. 4).
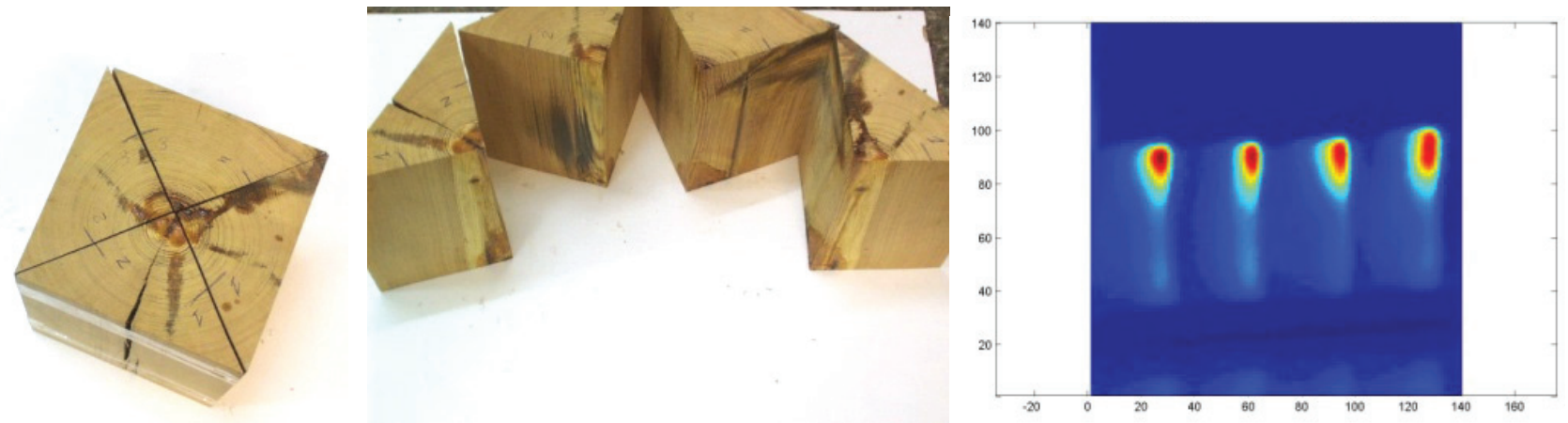

Fig. 4. Treated wood, sectioned element, thermographic image 


\section{Art Nouveau residential building in Valencia}

Description of the building. The object of the study case is a building erected in 1910 close to the port of Valencia, Spain. It is an Art Nouveau construction with a ground floor, two upper floors and an attic. During most of its existence the building had a shop on the ground floor and two apartments on the upper stories. These were abandoned in the nineteen-eighties and had been completely neglected until the beginning of the $21^{\text {st }}$ century $[7,8]$.

In the building, the load-bearing walls are made of brick masonry and the horizontal structures of floors and roof are made of timber. The horizontal frames are jack arch floors made with timber joists and timbrel brick vaults filled with gypsum conglomerate on top. The roof is built with timber rafters and laths that hold a layer of flat bricks and roof tiles on top (Fig. 5).

The wood employed for the joists in the whole building is Southern Yellow Pine from the forests of the south of USA. In fact, in the middle of the $19^{\text {th }}$ century, the local pine, traditionally used for construction (Pinus nigra and Pinus silvestris), which was transported from the interior of Valencia region down the Turia River, started to be scarce and made it necessary to import timber from the south of USA.

The microscopic identification of the Southern Yellow Pine was done by analyzing a number of samples under the optical microscope, with the collaboration of Nicola Macchioni, researcher at CNR-IVALSA, Italy.

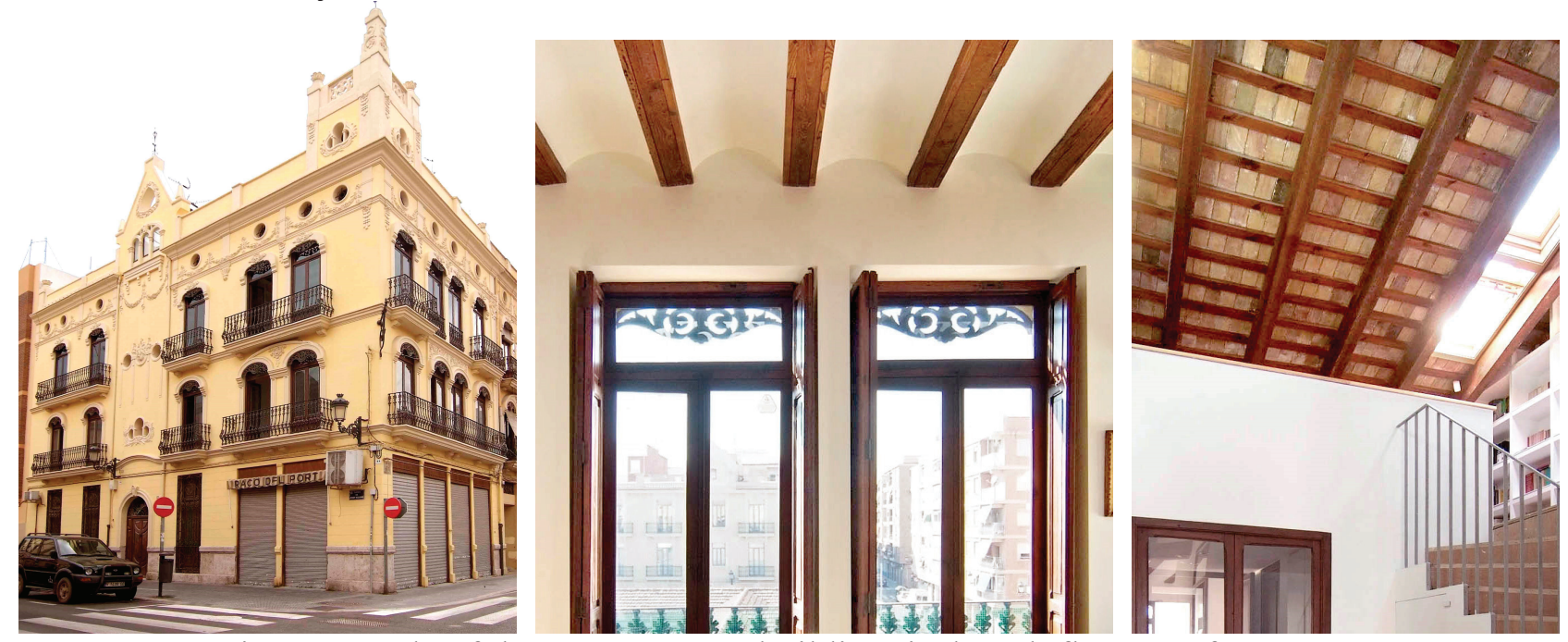

Fig. 5. Façade of the Art Nouveau building, jack arch floor, roof structure

The precarious state of the building. Due to the decades of neglect, at the moment of the restoration process, the building had numerous damages and pathologies. The brick masonry suffered the differential settlement of the building on the ground, which caused several cracks, even if they did not represented any threat to its stability. Nevertheless, the condition of the timber structure was very poor, mostly because of the leaks that caused the growth of brown rot on the roof structure, the ends of the purlins and the first floor near the western façade.

The damage in six timber joists of the first floor was clearly caused by the presence of an old compression layer of reinforced concrete that had been poured over the structure trying to reinforce it, with the unfortunate result of increasing the moisture content of timber and triggering the degradation process.

Moreover, the timber structure of the building showed signs of old damage caused by Cerambycidae and Anobiidae in the north-eastern corner of the attic and in several other places.

Conservation and treatments. [9] The restoration project intended to rehabilitate the building façade and both apartments to use them as residential units and update their equipment and installations standards. The necessary installations simply did not exist because the construction remained as it was originally built at the beginning of the $20^{\text {th }}$ century. 
The criteria applied to the restoration were based on the utmost respect for the original material nature of the building [10]. A priori, the substitution of structural elements was not discarded, but the goal was to avoid it wherever possible.

The possible presence of pregnant women and young children among future dwellers of the apartments advised against toxic treatments with noxious products dissolved in hydrocarbons. Although the time between the treatment and the occupancy of the building might have been long enough to dissipate the volatile substances, the doubts about whether the compound applied on the wood might later affect the inhabitants or not, remained. For this reason, the architects were induced to find completely harmless solutions for the treatment of wood.

The first step was the elimination of the main causes of timber degradation while the second phase was the attempt to directly take care of pathologies like the presence of insects.

The most important measure taken was to eliminate leaks and therefore reducing wood moisture content because it is the most important factor that triggers the degradation process. As a consequence, an efficient waterproofing was installed so that, not only rainwater infiltration was prevented, but also the increase of wood moisture content during the restoration work was avoided while the timber structure was kept ventilated as much as possible. All these precautions stopped the growth of brown rot and its degenerative action.

In the joists where rot damage on wood was concentrated, the mechanical properties and the residual resistance were low and unknown. Considering the fragility of the damaged joists and the fact that one of them was broken, these joists had to be completely reinforced by placing a metal plate in the intrados connected with bolts to a plywood panel on top of the extrados.

In the case of the old damages made by Cerambycidae, no intervention was considered necessary because this type of insects had left the building and was not expected to return because the natural loss of starch in the wood after 40-50 years following the trees felling, took away the attractive nutritional element for the insects' diet.

On the other hand, in the case of damages caused by Anobiidae, it was reasonably supposed that the elimination of the initial moisture content due to leaks might not be sufficient, so that it was also necessary to get rid of the larvae living inside the wood.

\section{Description of a pilot experiment}

Why the on-site pilot experiment. According to the intervention criteria of maximum health and minimum change explained before and taking into account all the factors and conditions concerning the building, the use of microwaves to treat timber against wood boring insects was considered an ideal solution. To prove its effectiveness and practicality in the architectural field, a pilot test with on-site microwave treatment was set up.

Previous investigations which had been carried out with this device and have been cited in the first chapter were conducted exclusively in laboratory with small pieces of wood and with a fine arts perspective directed to artistic wood objects with a painted or decorated surface like retablos and altarpieces.
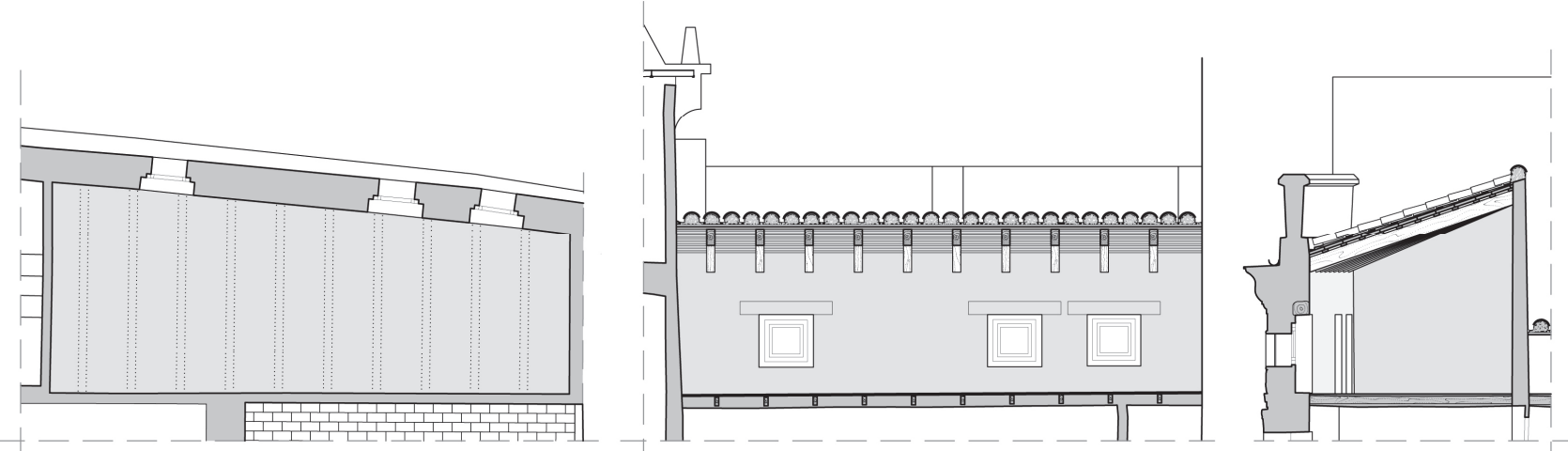

Fig. 6. Area of the attic object of the experiment, plan and sections 
Unlike experiments in laboratory, on-site applications of microwaves have to deal with more difficulties such as accessibility and the impossibility of removing the damaged elements in order to treat them. That is why it is useful to perform an on-site experiment that focuses specifically on bare timber used in architecture.

To be able to control the infestation, treatment, assessment and effectiveness recorded in the experiment, a limited and reduced area was used. So the object of the experiment was decided to be a separate wing of the attic (Fig. 6). The timber structure includes 10 rafters and 3 lintels on top of the 3 exterior windows.

Assessment. As a first step, the assessment was done visually and each element was closely examined to detect the presence of frass and recent exit holes, in addition to the old ones. The presence of Anobiidae insects was confirmed in several of the main elements as rafters and lintels, especially concentrated on the edges. Moreover, before the restoration works, adult insects were found all around the place and identified as Anobium punctatum. During the renovation process of the building the laths in the roof structure were substituted and so they were, for the moment, immune to the infestation.

Due to the location of the building, it was considered a real possibility the presence of termites. To confirm or reject their presence and, above all, to establish the extent of the attack, an acoustic detection was carried out thanks to the collaboration with Sabrina Palanti, researcher at CNRIVALSA, Italy.

The acoustic device has a sound receiver that is put in direct contact with wood, a portable instrument recording and mixing the sound with which is possible to regulate the volume and reduce background noise and finally incorporates headphones to be able to hear live the sound that insects make while eating wood. The sound is noticeable depending on the size of the larvae, so for example it was not possible to differentiate the sounds produced by the Anobium punctatum larvae from the background noise.

Acoustic detection was applied in each element of the structure and as the sound runs along the wood element, only few auscultation points were necessary. In detail: on each lintel and rafter the auscultation process was repeated twice near the two ends. In this way was possible to confirm the presence of xylophagous insects in the two eastern lintels, which most probably were Kalotermes flavicollis. In was also possible to verify that the attack had not spread to the rest of the structure.

The application of the microwaves. The application of microwaves was carried out in November 2012 to make sure the insects would be in the larva stage of their life cycle and therefore located inside the wood. (Fig. 7)

In order to reach the highest parts of the rafters the microwave transmitter antenna was subjected to an articulated arm while was secured to other supplementary structure to treat the easily accessible areas. During the treatment the flooring of the room was protected due to the possible liquefaction and dripping of the resin inside the timber.

In order to establish a proper application protocol several consideration were made.

Microwave antenna has a surface of $30 \times 30 \mathrm{~cm}$ but the real microwave emissions surface is slightly smaller and centred (Fig. 3), in addition, the intensity of the microwave decreases away from the centre. Similarly, the microwaves that penetrate into the wood are partially absorbed by it and their effectiveness decreases as the section of treated wood increase. For this reason, in structural wood is appropriate to apply the treatment on every visible or accessible surface and partially overlap the treated areas. As a result the antenna was moved with a separation of $15 \mathrm{~cm}$ rather than $30 \mathrm{~cm}$. These precautions ensure the maximum efficacy of the treatment and underline the differences with laboratory tests as they were carried out on wood elements with reduced thickness.

Moreover, in the case of the architectural timber used in the studied building, there are no paint or surface decorations that can be damaged as linseed oil was the only product applied to enrich wood and harmonize the colour. For this reason, to increase the effectiveness of the treatment, the 
application time was increased without worrying about chromatic variations. Each application, which corresponded to a particular position, lasted 1 minute with a power of $2 \mathrm{~kW}$, i.e. two magnetrons of $1 \mathrm{~kW}$ each. In this way, greater temperatures and depth were reached in comparison with the laboratory tests where an application of 20-30 seconds heated wood up to around the $60^{\circ} \mathrm{C}$.

While designing the procedure, the dimensions of elements and theoretical timing were taken into account.

The rafters have a section of around $10 \times 23 \mathrm{~cm}$ and a length between $200 \mathrm{~cm}$ and $280 \mathrm{~cm}$ and, in order to treat the Anobiidae infestation, microwaves were applied on both vertical side surfaces. Considering an average rafter of $240 \mathrm{~cm}$, a total of 30 applications were necessary and it took an average of 35 minutes for each rafter taking into account 10 second to change the position of the antenna. This means approximately 8 hours to finish the 10 rafters of the roof including the time necessary to move the device from one rafter to another which is considered to be 5 minutes.

In the case of the lintels, they have a section of $20 \times 17 \mathrm{~cm}$ and only two visible surfaces: the interior vertical surface, with a length of $120 \mathrm{~cm}$ and the intrados with a length of $70 \mathrm{~cm}$. A total of 11 applications were necessary and it took approximately 13 minutes for each lintel taking into account 10 second to change the position of the antenna. This means approximately 50 minutes to finish the 3 lintels including the time necessary to move the device from one rafter to another which is considered to be 5 minutes.

Because of the construction and section of the lintels it was possible that part of the wood inside the wall was not irradiated enough by microwaves. This is a very important variable that must be taken into account in the on-site application of microwave.

Finally the treatment of the whole timber structure took two days and required the presence of one worker to program and control the machine.
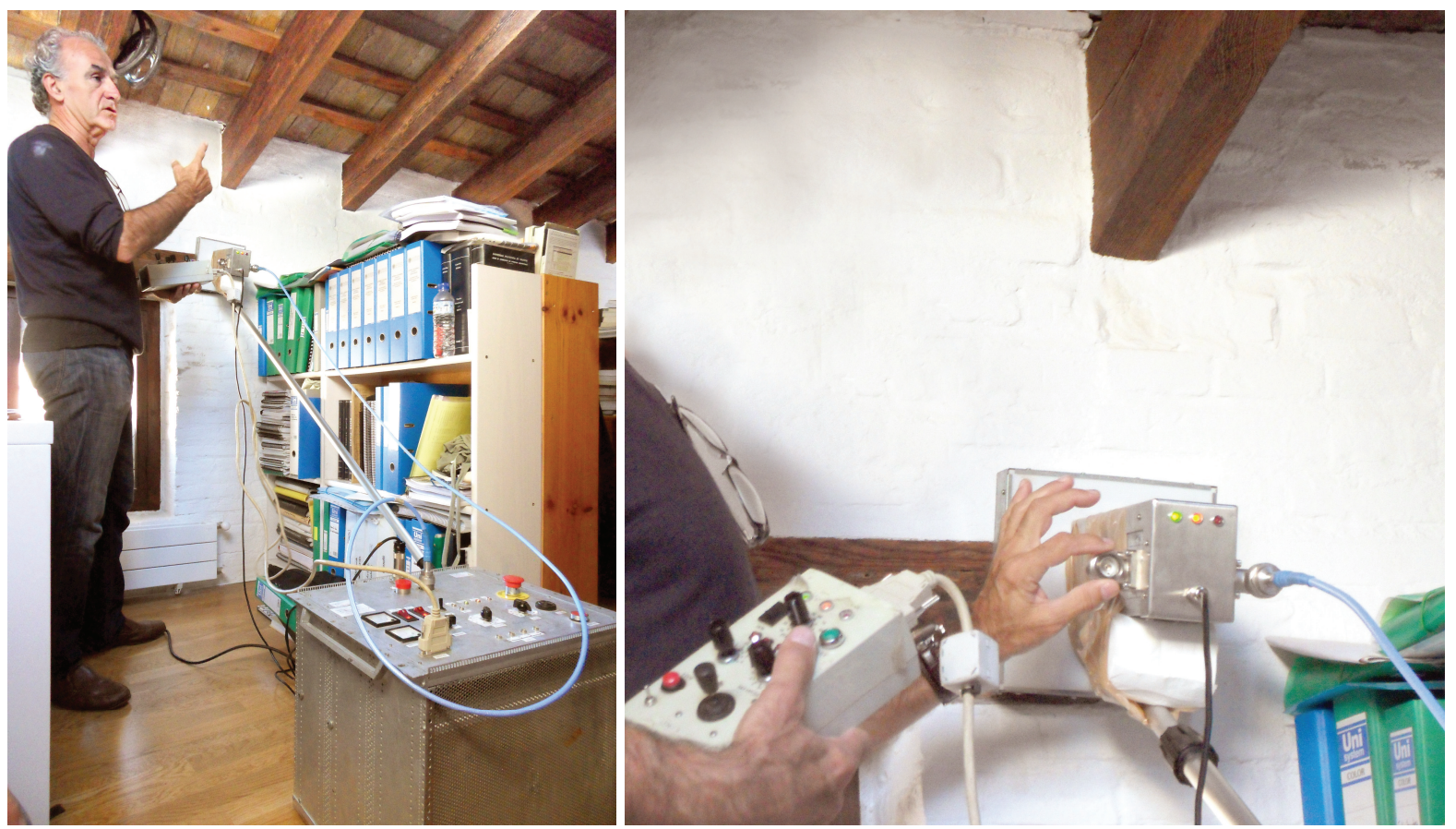

Fig. 7. Application of the microwave treatment on a timber lintel

\section{Results and conclusions}

The described pilot experiment proved that the proper study, knowledge and diagnosis of a historic timber structure make it possible not only to eliminate the original causes of the damages rather than just fixing the symptoms, but also to reduce the number of treatment. Among the possible treatments taken into account to eliminate a plague of wood boring insects, the use of Dryparasite microwave system was complying with the self-imposed conditions to ensure safety for the inhabitants and avoid any noxious product and without causing any damage to the historic structure. 
The effectiveness of the method was evaluated firstly with a visual recognition that highlighted that, even with grater time and power in the application of microwaves, no significant changes of colour or texture were observed neither during the treatment nor in the following weeks.

Concerning the Anobiidae the only confirmation of the efficacy of treatment was that no adult insects were detected during the spring.

In addition, the presence of wood boring insects in the lintels was tested. Once again, three months after the treatment, an acoustic detection assessment was carried out and detected that, despite the reduced application surface, the microwaves were effective and no sounds of the insects eating wood was heard.

Due to their social behaviour, in the case of termites, may not be enough to get rid of the insects found inside the lintels because, through their communication network, other individuals could reach the area. For this reason the treatment of microwave, while has proven its effectiveness also in architectural timber of considerable section, needs, in the case of termites, to be supported with other interventions in order to secure the perimeter and avoid a new attack of insects.

\section{References}

[1] T. Strang, Principles of Heat Disinfestation, Integrated Pest Management for Collections. Proceedings of: A Pest Odyssey a joint conference of English Heritage, the Science Museum and the National Preservation Office (2001).

[2] M. Bini, D. Andreuccetti, A. Ignesti, R. Olmi, S. Priori, R. Vanni, A portable microwave system for woodworm disinfestation of artistic painted boards, J. Microwave Power and Electromagnetic Energy, Vol. 32(3), (1997) 180-187.

[3] G. Torgovnikov, P. Vinde, Microwave Modification of Wood Properties: Improvements in Wood Permeability, 31st Annual Meeting of The international Research Group on Wood Preservation, Section 4. Processes and Properties (2000).

[4] E. Pérez Marín, M ${ }^{a}$ V. Vivancos Ramón, Aspectos técnicos y conservativos del retablo barroco valenciano, Universitat Politècnica de València, Valencia, 2004.

[5] $\mathrm{M}^{\mathrm{a}} \mathrm{V}$. Vivancos Ramón, E. Pérez Marín, Revisión crítica de los diferentes sistemas de desinfección aplicados a la retablística barroca, XIV Congreso de Conservación y Restauración de Bienes Culturales, Valladolid, 2002.

[6] Ma V. Vivancos Ramón, E. Pérez Marín, N. Valentin Rodrigo, La desinsectación de la madera, revisión de los últimos sistemas, Universitat Politècnica de València , Valencia, 2008.

[7] D. Benito Goerlich, La arquitectura del eclecticismo en Valencia. Vertientes de la arquitectura valenciana entre 1875 y 1925, Ayuntamiento deValencia, Valencia, 1983.

[8] M. Sanchis Guarner, La ciutat de València. Sintesi d'Història i de Geografia urbana, 6th edition, Generalitat Valenciana, Valencia 1997

[9] F. Vegas López-Manzanares, C. Mileto, New old restoration techniques for modernista buildings. Refurbishment of la Casa de la Madrina, in: AA.VV., International Seminar on the management of the Shared Mediterranean Heritage, Institute de Recherche pour le Developpment, Alexandria, 2005.

[10] F. Vegas López-Manzanares, C. Mileto, Aprendiendo a Restaurar, Generalitat Valenciana, Valencia, 2011. 